\title{
Comparação das metodologias da Farmacopéia Brasileira para determinação de água em matérias-primas vegetais, e validação da determinação de água em analisador de umidade para Calendula officinalis L., Foeniculum vulgare Miller, Maytenus ilicifolia Mart. ex. Reissek e Passiflora alata Curtis
}

\author{
D.B. Borges*, M.R. Farias, C.M.O. Simões, E.P. Schenkel \\ ${ }^{1}$ Departamento de Ciências Farmacêuticas, Universidade Federal de Santa Catarina, Campus Trindade, \\ 88040-900, Florianópolis, SC, Brasil
}

\begin{abstract}
RESUMO: No presente trabalho foi descrita a comparação da aplicabilidade das metodologias preconizadas na Farmacopéia Brasileira (1988) para a determinação de água em drogas vegetais. Foi realizada, ainda, a validação da determinação de água em analisador de umidade. As matérias-primas vegetais analisadas foram Calendula officinalis L. (calêndula), Foeniculum vulgare Miller (funcho), Maytenus ilicifolia Mart. ex. Reissek (espinheira-santa) e Passiflora alata Curtis (maracujá). A análise dos resultados obtidos mostrou que há diferenças estatisticamente significativas ( $<<0,05)$ entre as metodologias "Determinação de água por destilação azeotrópica" e "Determinação de água em drogas vegetais" em estufa, assim como, entre a "Determinação da perda por dessecação" para as drogas vegetais calêndula e funcho. No entanto, não foram observadas diferenças estatisticamente significativas $(p<0,05)$ entre as duas metodologias de secagem em estufa. Quanto à validação da determinação de água em analisador de umidade, não foram observadas diferenças estatisticamente significativas $(\mathrm{p}<0,05)$ entre os resultados das análises em analisador de umidade e os obtidos através da "Determinação da perda por dessecação". Além disso, não foram verificadas diferenças estatisticamente significativas $(\mathrm{p}<0,05)$ para as análises referentes à repetibilidade, precisão intermediária e reprodutibilidade da técnica, o que comprova a exatidão e a precisão da metodologia proposta.
\end{abstract}

Unitermos: Matérias-primas vegetais, determinação de água, metodologias farmacopéicas, analisador de umidade

\begin{abstract}
Comparison of pharmacopeial methods for water determination in plant raw materials and validation of water determination by infrared drying for Calendula officinalis, Foeniculum vulgare, Maytenus ilicifolia e Passiflora alata". A comparison of the Brazilian pharmacopeial methodologies for water determination in plant raw materials is presented for the following species: Calendula officinalis, Foeniculum vulgare, Maytenus ilicifolia e Passiflora alata. In addition, the validation of water determination by infrared drying was carried out for these species. The results obtained using the azeotropic distillation method (Brazilian Pharmacopoeia - "Determination of Water by Azeotropic Distillation") were significantly different $(p<0.05)$ than those obtained using two different gravimetric methods (Brazilian Pharmacopoeia - "Determination of Water in Vegetable Drugs" and "Determination of loss on Drying"). However, no significant statistical difference was observed between the two gravimetric methodologies. After optimization of operating conditions, the results of water determination by infrared drying were not significantly different than those obtained using the loss on drying pharmaceutical method. Also, no statistically significant differences were observed for repeatability, intermediate precision and reproducibility of the method, demonstrating the accuracy and precision of the proposed methodology.
\end{abstract}

Keywords: Vegetal drugs, determination of water, infrared drying.

\section{INTRODUÇÃO}

O excesso de água em matérias-primas vegetais possibilita a ação de enzimas, além de propiciar o desenvolvimento de fungos e bactérias (Farias, 2003). Entre os métodos analíticos oficiais para determinação de água em matérias-primas vegetais, o método gravimétrico em estufa é o mais comum, seguido do método de destilação azeotrópica, preconizado para a determinação de água em drogas vegetais ricas em óleos voláteis.

Os métodos de secagem em estufa determinam não somente a perda de água, como também dos demais constituintes volatilizados juntamente com a água (Isengard; Färber,. 1999; Farias, 2003). Além disso, 
apresentam problemas quanto à reprodutibilidade dos resultados, pois variações significativas podem ser observadas quando uma mesma amostra é analisada em laboratórios diferentes e sob condições climáticas variadas, principalmente, em relação à umidade relativa do ar (Isengard et al, 2001).

A Farmacopéia Brasileira (2000a) preconiza a determinação de água para matérias-primas vegetais no item V.4.2.3 "Determinação de água em drogas vegetais”, onde, além dos métodos citados anteriormente (gravimétrico e azeotrópico), indica o método volumétrico (Karl Fisher), e alega que o método gravimétrico é tecnicamente o mais simples e rápido, mas não deve ser aplicado para matérias-primas vegetais que contenham outras substâncias voláteis além da água. A Farmacopéia menciona, ainda, que o método deve ser selecionado de acordo com a respectiva monografia; entretanto, nas monografias existentes não há especificação de qual dessas metodologias deve ser empregada para a obtenção do valor de referência estabelecido.

Em relação ao método gravimétrico, a Farmacopéia Brasileira (1988) preconiza, ainda, nos Métodos Gerais, a "Determinação da perda por dessecação" (V.2.9). As duas metodologias de secagem em estufa diferem quanto aos critérios de análise. Enquanto a "Determinação de água em drogas vegetais" preconiza a secagem em estufa de 2,0 a 5,0 g da amostra, exatamente pesados, por $5 \mathrm{~h}$, a $100-105^{\circ} \mathrm{C}$ e considera a análise concluída quando a diferença entre duas pesagens consecutivas for menor do que 5,0 mg, a "Determinação da perda por dessecação" preconiza a secagem em estufa de $1,0 \mathrm{~g}$ da amostra, por $2 \mathrm{~h}$, a $100-105^{\circ} \mathrm{C}$, mas só considera a análise concluída quando a amostra atingir o peso constante, ou seja, quando a diferença entre duas pesagens consecutivas não diferir em mais de $0,5 \mathrm{mg}$ por grama da amostra.

Apesar da existência de metodologias oficiais, atualmente, estudos estão sendo realizados sobre o uso de balanças acopladas a sistemas de secagem por radiação infravermelha (analisador de umidade) para a determinação de água, tanto na área de alimentos quanto na área de medicamentos (Berntsson, Zackrisson, Östing, 1997; Isengard; Färber, 1999; Isengard et al, 2001; De Caro, Aichert, Walter, 2001; Isengard; Präger, 2003), o que é explicável em função do longo período de tempo requerido para a realização das análises através das técnicas clássicas.

O princípio do aquecimento por radiação infravermelhaéatransformaçãodaenergiaeletromagnética em energia cinética, com liberação de energia térmica. Em contraste com a transferência de calor por convecção, na secagem em estufa, a energia térmica fornece quantidade de calor suficiente para que a liberação das moléculas de água ocorra mais rapidamente. Cabe ressaltar que, como na secagem em estufa, a medida da perda de massa inclui não somente a água (Isengard; Präger, 2003). No entanto, há poucos estudos sistemáticos sobre o uso desta técnica aplicada a matérias-primas vegetais, pois dependendo do aparelho utilizado para a determinação de água, diferentes programações podem ser feitas e os resultados das análises podem variar, dependendo do programa selecionado (Isengard,1995; Isengard; Färber, 1999). Diante disso, faz-se necessário validar a metodologia de determinação de água através de analisador de umidade, de acordo com as condições de secagem estabelecidas.

No presente trabalho é descrita a comparação da aplicabilidade das seguintes metodologias farmacopéicas: "Determinação de água em drogas vegetais”, “Determinação da perda por dessecação” e "Determinação de água por destilação azeotrópica” para as seguintes matérias-primas vegetais: Calendula officinalis L. (calêndula), Foeniculum vulgare Miller (funcho) Maytenus ilicifolia Mart ex. Reissek. (espinheira-santa) e Passiflora alata Curtis (maracujá). Além disso, foi realizada a validação da metodologia de determinação de água em analisador de umidade para essas mesmas plantas.

\section{MATERIAL E MÉTODOS}

\section{Material vegetal}

Os lotes das espécies analisadas (inflorescências de Calendula officinalis L. - calêndula, folhas de Maytenus ilicifolia Mart. ex. Reissek - espinheira-santa, frutos de Foeniculum vulgare Miller - funcho e partes aéreas de Passiflora alata Curtis - maracujá) foram adquiridos junto à Cooperativa de Pequenos Agricultores de Estado de Santa Catarina, através da empresa Shambala, em quantidade suficiente para a realização de todas as análises (1,0 Kg de cada planta). Os materiais vegetais foram triturados em moinho de facas (Maqmont) e tamisados para viabilizar a obtenção das granulometrias sugeridas pela Organização Mundial da Saúde (1998): calêndula (500), espinheira-santa (350), funcho (710), e maracujá (350). Os mesmos foram acondicionados em recipiente de vidro, devidamente fechados, armazenados em ambiente com temperatura controlada $\left(18^{\circ} \mathrm{C}\right)$ e protegidos da luz.

\section{Determinação de água segundo metodologias farmacopéicas}

A determinação de água para calêndula, espinheira-santa, funcho e maracujá foi realizada segundo as metodologias: "Determinação da perda por dessecação"; "Determinação de água em drogas vegetais" em estufa (V.4.2.3) e "Determinação de água por destilação azeotrópica” (V.2.20.2), preconizadas na Farmacopéia Brasileira. Na determinação de água por destilação azeotrópica, a água destilada juntamente com o tolueno, antes e após a adição da droga vegetal, foi transferida para tubo de centrifuga graduado e, em seguida, centrifugado, sendo que o volume de água da amostra foi obtido através da diferença dos volumes final 
e do inicial. Os resultados obtidos foram expressos através da média \pm desvio padrão (DP) de oito determinações, em porcentagens. Todas as análises foram realizadas com a umidade relativa do ar inferior a $90 \%$.

\section{Determinação de água através de analisador de umidade}

A determinação de água em analisador de umidade foi realizada em dois laboratórios (Laboratório de Farmacognosia da Universidade Federal de Santa Catarina e no Laboratório Farmacêutico do Estado de Santa Catarina - LAFESC). Para a realização das análises foram utilizados dois analisadores de umidade: o da marca Ohaus, modelo MB 45 (EUA) e o da marca Metller Toledo, modelo HB 43 (Suíça). Em ambos, a fonte de aquecimento é uma lâmpada de halogênio (400 W) e a sensibilidade da balança é de 0,001 g. Os parâmetros de análise empregados foram: a) massa das amostras: $1,00 \mathrm{~g}$; b) temperatura de análise: $105^{\circ} \mathrm{C}$; c) término da análise: perda menor que $1 \mathrm{mg}$ em 120 e 140 segundos; e) Intervalo entre as análises: $30 \mathrm{~min}, 2 \mathrm{~min}$ e sem intervalos.

Validação da metodologia de determinação de água em analisador de umidade

A validação foi realizada utilizando-se as drogas vegetais citadas anteriormente. Os ensaios foram realizados de acordo a Conferência Internacional de Harmonização (ICH, 1998) e com o Guia de Validação de Métodos Analíticos e Bio-analíticos (Brasil, 2003). A exatidão foi avaliada através da relação entre os resultados obtidos em analisador de umidade com os obtidos através da metodologia farmacopéica "Determinação da perda por dessecação”, em porcentagem (Brasil, 2003). Os resultados obtidos através da metodologia farmacopéica foram registrados e considerados como valores de referências para avaliar o grau de concordância com os resultados obtidos por intermédio da determinação de água em analisador de umidade. Para determinação de água em analisador de umidade, os resultados foram obtidos pela leitura direta no visor do aparelho, em porcentagens. A precisão da metodologia proposta foi avaliada através da análise da dispersão dos resultados entre os ensaios independentes, repetidos para a mesma amostra, expressos por meio da repetibilidade, precisão intermediária e da reprodutibilidade. A repetibilidade foi avaliada através de medições sucessivas da mesma amostra, efetuadas sob as mesmas condições (mesmo procedimento de medição; mesmo analista; mesmo equipamento, usado sob as mesmas condições; mesmo laboratório) e com oito determinações ao dia. A precisão intermediária foi avaliada através dos resultados das 8 determinações realizadas para uma mesma amostra, obtidos através de dois analistas durante um período de 7 dias. A reproditibilidade foi avaliada através da concordância entre os resultados obtidos através das 8 determinações realizadas no segundo laboratório, durante um período de 7 dias. A dispersão dos resultados foi avaliada através dos desvios padrões (DP) e do coeficiente de variação $(\mathrm{CV})$, não se admitindo valores superiores a 5\% (Brasil, 2003).

\section{Análise estatística}

Os resultados obtidos na determinação de água, através das metodologias farmacopéicas, assim como, através do analisador de umidade foram analisados empregando-se o teste $t$ de Student, com significância de $\mathrm{p}<0,05$.

\section{RESULTADOS E DISCUSSÃO}

\section{Determinação de água segundo metodologias farmacopéicas}

Os resultados obtidos através das metodologias farmacopéicas "Determinação da perda por dessecação", "Determinação de água em drogas vegetais" e “Determinação de água por destilação azeotrópica” são apresentados na Tabela 1.

Quanto aos resultados obtidos através da "Determinação de água em drogas vegetais" e da "Determinação de água por destilação azeotrópica”, não foram observadas diferenças estatisticamente significativa para o maracujá e para a espinheira-santa. No entanto, foram observadas diferenças estatisticamente significativas entre os resultados obtidos para calêndula e para o funcho, sendo essas, duas espécies que contêm óleos voláteis (Bisset, 1994).

A Farmacopéia Brasileira IV preconiza um teor máximo de $12 \%$ para calêndula (Farmacopéia Brasileira, 2001) e 10\% para funcho (Farmacopéia Brasileira, 2000b), e portanto, as duas amostras estariam reprovadas, pois os resultados obtidos foram, respectivamente, 13,33\% e $10,41 \%$. No entanto, ambas seriam aprovadas, segundo os resultados obtidos através da destilação azeotrópica, a saber, 9,1\% e 8,2\% respectivamente. É importante observar que apenas o funcho é considerado rica em óleo volátil, o que realça a importância de especificar nas respectivas monografias qual metodologia deve ser empregada para a determinação de água.

$\mathrm{Na}$ comparação dos resultados obtidos através da "Determinação da perda por dessecação" e da "Determinação de água em drogas vegetais", foi observada diferença estatisticamente significativa apenas para a calêndula, que poderia estar relacionada com a presença de óleo volátil e/ou de outros constituintes termo-sensíveis dependentes do tempo de exposição ao calor.

Em relação ao tempo total de análise para a “Determinação da perda por dessecação” e da "Determinação de água em drogas vegetais", observou-

Rev. Bras. Farmacogn. Braz J. Pharmacogn. 15(3):jul/set. 2005 
Tabela 1. Teores de água nas drogas vegetais Calendula officinalis (calêndula), Maytenus ilicifolia (espinheira-santa), Foeniculum vulgare (funcho) e Passiflora alata (maracujá), através das metodologias "Determinação de água em drogas vegetais”, “Determinação de água por destilação azeotrópica” e "Determinação da perda por dessecação” (n= 8).

\begin{tabular}{l|c|c|c}
\hline Droga vegetal & $\begin{array}{c}\text { Determinação de água em } \\
\text { drogas vegetais } \\
\overline{\mathrm{X}} \pm \mathrm{DP} \\
(\mathrm{CV} \%)\end{array}$ & $\begin{array}{c}\text { Determinação de água por } \\
\text { destilação azeotrópica } \\
\overline{\mathrm{X}} \pm \mathrm{DP} * \\
(\mathrm{CV} \%)\end{array}$ & $\begin{array}{c}\text { Determinação } \\
\text { da perda por dessecação } \\
\overline{\mathrm{X}} \pm \mathrm{DP} \\
(\mathrm{CV} \%)\end{array}$ \\
\hline Calêndula & $13,33 \pm 0,44^{\mathrm{a}, \mathrm{c}}$ & $9,1 \pm 0,4^{\mathrm{a}}$ & $(4,9)$ \\
Espinheira-santa & $(3,31)$ & $7,2 \pm 0,3$ & $\begin{array}{c}12,44 \pm 0,50^{\mathrm{c}} \\
(4,03)\end{array}$ \\
Funcho & $7,19 \pm 0,24$ & $(3,60)$ & $7,29 \pm 0,12$ \\
& $(3,31)$ & $8,2 \pm 0,5^{\mathrm{b}}$ & $(1,70)$ \\
Maracujá & $10,41 \pm 0,23^{\mathrm{b}}$ & $(6,1)$ & $10,54 \pm 0,18$ \\
& $(2,22)$ & $10,5 \pm 0,3$ & $(1,77)$ \\
& $10,58 \pm 0,26$ & $(3,0)$ & $10,51 \pm 0,21$ \\
\end{tabular}

Letras iguais indicam diferença estatisticamente significativa entre si (teste- $t$ studant, $\mathrm{p}<0,05$ ); * Na Determinação de água por destilação azeotrópica os resultados são apresentados com precisão de 0,1 mL.

Tabela 2. Tempo médio total $(n=8)$ necessário para a realização das metodologias "Determinação da Perda por dessecação", “Determinação de água em drogas vegetais” e "Determinação de água por destilação azeotrópica” nas drogas vegetais calêndula, espinheira-santa, funcho e maracujá.

\begin{tabular}{l|c|c|c}
\hline Droga vegetal & $\begin{array}{c}\text { Determinação de água } \\
\text { drogas vegetais }\end{array}$ & $\begin{array}{c}\text { Determinação de água por } \\
\text { destilação azeotrópica }\end{array}$ & $\begin{array}{c}\text { Determinação da perda } \\
\text { por dessecação }\end{array}$ \\
\hline Calêndula & $8: 30$ & $3: 30$ & $5: 30$ \\
Espinheira-santa & $7: 30$ & $3: 30$ & $5: 30$ \\
Funcho & $7: 30$ & $3: 30$ & $7: 30$ \\
Maracujá & $9: 30$ & $3: 30$ & 5 \\
\hline
\end{tabular}

se que, apesar de existirem diferenças entre os dois procedimentos operacionais, ambos são demasiadamente longos, exigindo a dedicação dos operadores durante quase todo o procedimento. Quanto ao método azeotrópico, o tempo total de análise foi praticamente a metade do tempo necessário para a realização da "Determinação da perda por dessecação” (Tabela 2), sem considerar o tempo necessário a montagem dos aparelhos de destilação.

Na "Determinação de água em drogas vegetais", constatou-se que é necessário um número menor de pesagens atéobter a diferença demassa, entreduas pesagens sucessivas, menor que o preconizado na metodologia (5,0 mg). Na "Determinação da perda por dessecação”, a maior dificuldade encontrada foi a necessidade de chegar ao peso constante, pois observou-se que, a partir de um determinado ponto, algumas amostras passavam a absorver umidade do ambiente e, conseqüentemente, aumentavam de peso, enquanto outras continuavam a perdendo-o; no entanto, os valores dos teores de água não variavam mais. Observou-se também que, apesar de não se chegar a peso constante, as diferenças obtidas entre as duas últimas pesagens consecutivas foram maiores que $0,5 \mathrm{mg}$, porém menores que $1,0 \mathrm{mg}$. Diante desta constatação, considerou-se a análise concluída quando não foram observadas variações entre as médias de duas pesagens sucessivas (Tabela 3).

Ainda em relação ao estabelecimento do término das análises, foi feita a comparação dos resultados da determinação de água, obtidos através da "Determinação da perda por dessecação" quando a diferença entre duas pesagens consecutivas foi menor que 1,0 mg e 5,0 mg. Os resultados são apresentados na Tabela 4, onde pode-se verificar, que não foram observadas diferenças estatisticamente significativas entre os resultados obtidos.

Quanto à "Determinação de água em drogas vegetais”, constatou-se que os coeficientes de variação obtidos para as quatro plantas analisadas, ao final de cada 
Tabela 3. Teores de água nas drogas vegetais Calendula officinalis (calêndula), Maytenus ilicifolia (espinheira-santa), Foeniculum vulgare (funcho) e Passiflora alata (maracujá), obtidas através das metodologias "Determinação de água em drogas vegetais” e "Determinação da perda por dessecação”, após cada uma das pesagens realizadas ( $\mathrm{n}=8)$.

\begin{tabular}{|c|c|c|c|c|c|}
\hline & 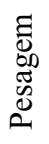 & $\begin{array}{l}\text { Calêndula } \\
\bar{X} \pm \mathrm{DP} \\
(\mathrm{CV} \%)\end{array}$ & $\begin{array}{c}\text { Espinheira-santa } \\
\overline{\mathrm{X}} \pm \mathrm{DP} \\
(\mathrm{CV} \%)\end{array}$ & 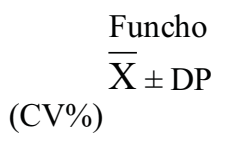 & ${ }_{(\mathrm{CV} \%)^{\frac{\text { Maracujá }}{\mathrm{X}} \pm \mathrm{DP}}}$ \\
\hline 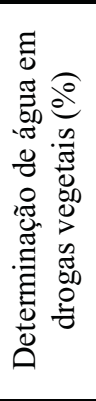 & $\begin{array}{l}1^{\mathrm{a}} \\
2^{\mathrm{a}} \\
3^{\mathrm{a}} \\
4^{\mathrm{a}} \\
5^{\mathrm{a}}\end{array}$ & $\begin{array}{c}9,81 \pm 1,73 \\
(17,68) \\
12,00 \pm 0,51 \\
(4,28) \\
12,44 \pm 0,41 \\
(3,26) \\
12,44 \pm 0,50 \\
(4,03) \\
-\end{array}$ & $\begin{array}{c}7,16 \pm 0,23 \\
(3,23) \\
7,19 \pm 0,24 \\
(3,31) \\
- \\
- \\
-\end{array}$ & $\begin{array}{c}9,84 \pm 0,20 \\
(2,01) \\
10,17 \pm 0,21 \\
(2,04) \\
10,29 \pm 0,22 \\
(2,17) \\
10,45 \pm 0,23 \\
(2,20) \\
10,51 \pm 0,21 \\
(2,04)\end{array}$ & $\begin{array}{c}10,50 \pm 0,22 \\
(2,07) \\
10,48 \pm 0,18 \\
(1,76) \\
10,41 \pm 0,18 \\
(1,77) \\
- \\
-\end{array}$ \\
\hline 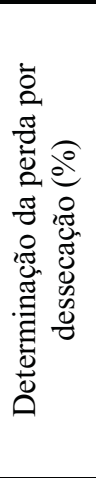 & $\begin{array}{l}1^{\mathrm{a}} \\
2^{\mathrm{a}} \\
3^{\mathrm{a}} \\
4^{\mathrm{a}}\end{array}$ & $\begin{array}{c}12,61 \pm 0,36 \\
(2,38) \\
13,24 \pm 0,40 \\
(3,04) \\
13,33 \pm 0,44 \\
(3,27) \\
13,34 \pm 0,45 \\
(3,36) \\
13,32 \pm 0,42 \\
(3,13) \\
13,33 \pm 0,44 \\
(3,31)\end{array}$ & $\begin{array}{c}7,21 \pm 0,15 \\
(2,03) \\
7,27 \pm 0,11 \\
(1,49) \\
7,29 \pm 0,12 \\
(1,70) \\
- \\
- \\
-\end{array}$ & $\begin{array}{c}10,09 \pm 0,37 \\
(3,69) \\
10,53 \pm 0,27 \\
(2,52) \\
10,54 \pm 0,31 \\
(2,95) \\
10,57 \pm 0,29 \\
(2,78) \\
10,57 \pm 0,27 \\
(2,59) \\
10,58 \pm 0,26 \\
(2,42)\end{array}$ & $\begin{array}{c}10,63 \pm 0,42 \\
(3,91) \\
10,46 \pm 0,20 \\
(1,87) \\
10,49 \pm 0,24 \\
(2,26) \\
10,54 \pm 0,23 \\
(2,22) \\
- \\
-\end{array}$ \\
\hline
\end{tabular}

análise, foram semelhantes aos obtidos na "Determinação da perda por dessecação” (Tabela 3). Cabe ressaltar que a quantidade de amostra utilizada na primeira técnica foi três vezes maior do que a utilizada na segunda; além disso, o tempo de secagem na estufa da primeira é mais que o dobro da segunda. No entanto, os resultados obtidos não apresentaram diferenças estatisticamente significativas, o que representa um gasto maior em termos de energia, tempo e mão de obra, quando da execução da "Determinação de água em drogas vegetais".

Diante da similaridade dos resultados apresentados e das vantagens acima expostas propõe-se que o teor de água em drogas vegetais seja realizado de acordo com a metodologia "Determinação da perda por dessecação”, considerando-se a análise concluída quando a diferença entre duas pesagens consecutivas for menor do que $5 \mathrm{mg}$.

\section{Determinação de água através de analisador de umidade}

Nesta metodologia, os parâmetros de análise (massa da amostra e temperatura de análise) foram selecionados de acordo com os parâmetros

Tabela 4. Teores de água nas drogas vegetais Calendula officinalis (calêndula), Maytenus ilicifolia (espinheira-santa), Foeniculum vulgare (funcho) e Passiflora alata (maracujá), obtidos através da metodologia “Determinação da perda por dessecação”, após duas pesagens consecutivas, cujas, diferenças foram menores que 5,0 ou 1,0 mg $(\mathrm{n}=8)$.

\begin{tabular}{c|c|c|c|c}
\hline & $\begin{array}{c}\text { Calêndula } \\
\bar{X} \pm \mathrm{DP}\end{array}$ & $\begin{array}{c}\text { Espinheira-santa } \\
\overline{\mathrm{X}} \pm \mathrm{DP} \\
(\mathrm{CV} \%)\end{array}$ & $\begin{array}{c}\text { Funcho } \\
\mathrm{X} \pm \mathrm{DP} \\
(\mathrm{CV} \%)\end{array}$ & $\begin{array}{c}\text { Maracujá } \\
\overline{\mathrm{X}} \pm \mathrm{DP} \\
(\mathrm{CV} \%)\end{array}$ \\
\hline Diferença $<$ & $13,33 \pm 0,44$ & $7,29 \pm 0,12$ & $10,54 \pm 0,23$ & $10,58 \pm 0,26$ \\
$1,0 \mathrm{mg} *$ & $(3,31)$ & $(1,70)$ & $(2,22)$ & $(2,42)$ \\
Diferença $<$ & $13,33 \pm 0,44$ & $7,21 \pm 0,15$ & $10,49 \pm 0,24$ & $10,54 \pm 0,31$ \\
$5,0 \mathrm{mg} *$ & $(3,27)$ & $(2,03)$ & $(2,26)$ & $(2,95)$ \\
\hline
\end{tabular}

* diferença de massa entre duas pesagens consecutivas. 
Tabela 5. Teores de água nas drogas vegetais Calendula officinalis (calêndula), Maytenus ilicifolia (espinheira-santa), Foeniculum vulgare (funcho) e Passiflora alata (maracujá), obtidos através da “Determinação da perda por dessecação” e em analisador de umidade $(\mathrm{n}=8)$.

\begin{tabular}{l|c|c|c}
\hline \multirow{2}{*}{$\begin{array}{l}\text { Droga } \\
\text { vegetal }\end{array}$} & $\begin{array}{c}\text { Determinação da perda por } \\
\text { dessecação }\end{array}$ & $\begin{array}{c}\text { Determinação de água em } \\
\text { analisador de umidade }\end{array}$ & $\begin{array}{c}\text { Exatidão } \\
(\%)\end{array}$ \\
\hline Calêndula & $\begin{array}{c}\bar{X} \pm \mathrm{DP} \\
(\mathrm{CV} \%)\end{array}$ & $\begin{array}{c}\mathrm{XP} \\
(\mathrm{CV} \%)\end{array}$ & 100,00 \\
Espinheira-santa & $8,27 \pm 0,16$ & $8,27 \pm 0,11$ & 102,25 \\
Funcho & $(1,96)$ & $6,37 \pm 0,13$ & $(1,97)$ \\
Maracujá & $6,23 \pm 0,12$ & $8,44 \pm 0,12$ & $(1,36)$ \\
& $(1,97)$ & $8,46 \pm 0,13$ & 98,14 \\
& $8,60 \pm 0,17$ & $(1,49)$ & 99,41 \\
\hline
\end{tabular}

preconizados na metodologia "Determinação da perda por dessecação”. Um ponto crítico para a determinação do teor de água através do analisador de umidade, e que não pôde ser estabelecido de acordo com as metodologias farmacopéicas, está relacionado com o término das análises. Nos dois aparelhos utilizados, após testes preliminares, selecionou-se, entre as opções de programação existentes, aquela que apresentou resultados mais próximos aos obtidos através da "Determinação da perda por dessecação”. No analisador de umidade Ohau, MB45, o critério selecionado para o término da análise foi: perda de massa menor do que 1,0 mg em 120 segundos; e no analisador de Umidade Metller Toledo, MB43, foi a perda de massa menor do que 1,0 mg em 140 segundos.

Outro aspecto importante a ser observado é o intervalo entre as análises. Segundo Isengard e Fäber (1999), os resultados da determinação de água em analisador de umidade dependem da temperatura em que o equipamento se encontra no início de cada análise. Por isso, com relação ao intervalo entre as análises testouse a utilização do aparelho quente e sem intervalos; a utilização do aparelho frio, ou seja, com 30 minutos de intervalo entre as análises; e a sua utilização com 2 min de intervalo entre o final de uma análise e o início de outra.

Para as análises realizadas com o aparelho quente e sem intervalos entre as análises observou-se que ocorre uma perda de massa substancial, antes mesmo do início da análise, o que leva a resultados errôneos. Para as análises realizadas com o aparelho frio, observou-se que os resultados obtidos são bastante precisos (dados não mostrados), no entanto, ao utilizar o aparelho frio, o intervalo necessário para a realização das análises (30 min), caracteriza-se como uma desvantagem em relação ao tempo total das análises. Ao fixar o intervalo de tempo entre o final de uma análise e o início de outra em 2 min, observou-se que os resultados das medições foram similares e com baixos coeficientes de variação e, com isto, viabilizou-se o tempo total para a realização das análises, corroborando com os resultados apresentados por Isengard e Färber,1999; Isengard e colaboradores, 2001.

\section{Validação da metodologia de determinação de água} em analisador de umidade

Após o estabelecimento dos parâmetros de análise, realizou-se a validação da metodologia proposta para as quatro drogas vegetais em estudo. Tendo em vista os resultados obtidos anteriormente através da comparação das metodologias farmacopéicas, a exatidão da metodologia proposta em analisador de umidade foi avaliada através do quociente entre os resultados obtidos com o analisador de umidade da marca Ohaus, com aqueles obtidos através da "Determinação da Perda por dessecação”, considerando como critério para o término da análise a diferença menor que 5,0 mg entre duas pesagens sucessivas. A análise estatística dos resultados mostrou que não houve diferenças estatisticamente significativas $(\mathrm{p}<0,05)$ entre os resultados obtidos através do uso do analisador de umidade, levando-se em conta os parâmetros de análise fixados e os resultados da “Determinação da perda por dessecação” (Tabela 5).

Quanto a precisão, os coeficientes de variação (CV\%) obtidos através das análises, relativas a repetibilidade, precisão intermediária e a reprodutibilidade, em analisador de umidade foram menores do que $2 \%$. Além disso, não foram verificadas diferenças estatisticamente significativas $(p<0,05)$ entre os resultados obtidos paras as mesmas, confirmando, assim, a precisão da metodologia proposta (Tabela 6).

\section{CONCLUSÃO}

Os resultados apresentados demonstram a importância de especificar nas monografias farmacopéicas a metodologia a ser empregada para a determinação do teor de água em drogas vegetais. Ao contrário do mencionado na Farmacopéia Brasileira (1988), este trabalho demonstra que as metodologias de secagem em estufa são demasiadamente longas, exigindo a dedicação 
Tabela 6. Teores de água nas drogas vegetais Calendula officinalis (calêndula), Maytenus ilicifolia (espinheira-santa), Foeniculum vulgare (funcho) e Passiflora alata (maracujá), obtidas através das análises, em analisador de umidade, relativas a repetibilidade, precisão intemediária e reprodutibilidade $(\mathrm{n}=8)$.

\begin{tabular}{|c|c|c|c|c|c|c|}
\hline & \multicolumn{3}{|c|}{ Calêndula } & \multicolumn{3}{|c|}{ Funcho } \\
\hline & Condição 1 & Condição 2 & Condição 3 & Condição 1 & Condição 2 & Condição 3 \\
\hline Dia & $\begin{array}{l}\mathrm{X} \pm \mathrm{DP} \\
(\mathrm{CV} \%)\end{array}$ & $\begin{array}{l}\mathrm{X} \pm \mathrm{DP} \\
(\mathrm{CV} \%)\end{array}$ & $\begin{array}{l}X \pm D P \\
(C V \%)\end{array}$ & $\begin{array}{l}\mathrm{X} \pm \mathrm{DP} \\
(\mathrm{CV} \%)\end{array}$ & $\begin{array}{l}\mathrm{X} \pm \mathrm{DP} \\
(\mathrm{CV} \%)\end{array}$ & $\begin{array}{l}\mathrm{X} \pm \mathrm{DP} \\
(\mathrm{CV} \%)\end{array}$ \\
\hline 1 & $\begin{array}{c}8,38 \pm 0,18 \\
(2,10)\end{array}$ & $\begin{array}{c}8,32 \pm 0,24 \\
(2,85)\end{array}$ & $\begin{array}{c}8,50 \pm 0,15 \\
(1,76)\end{array}$ & $\begin{array}{c}8,38 \pm 0,26 \\
(3,16)\end{array}$ & $\begin{array}{c}8,51 \pm 0,13 \\
(1,53)\end{array}$ & $\begin{array}{c}8,62 \pm 0,23 \\
(2,64)\end{array}$ \\
\hline 2 & $\begin{array}{c}8,21 \pm 0,17 \\
(2,03)\end{array}$ & $\begin{array}{c}8,30 \pm 0,11 \\
\quad(1,37)\end{array}$ & $\begin{array}{c}8,21 \pm 0,14 \\
\quad(1,67)\end{array}$ & $\begin{array}{c}8,55 \pm 0,14 \\
\quad(1,63)\end{array}$ & $\begin{array}{c}8,39 \pm 0,15 \\
(1,80)\end{array}$ & $\begin{array}{c}8,42 \pm 0,18 \\
\quad(2,13)\end{array}$ \\
\hline 3 & $\begin{array}{c}8,31 \pm 0,13 \\
\quad(1,55)\end{array}$ & $\begin{array}{c}8,55 \pm 0,16 \\
(1,84)\end{array}$ & $\begin{array}{c}8,47 \pm 0,21 \\
\quad(2,43)\end{array}$ & $\begin{array}{c}8,30 \pm 0,24 \\
\quad(2,93)\end{array}$ & $\begin{array}{c}8,63 \pm 0,18 \\
(2,11)\end{array}$ & $\begin{array}{c}8,38 \pm 0,19 \\
\quad(2,26)\end{array}$ \\
\hline 4 & $\begin{array}{c}8,22 \pm 0,16 \\
(1,96)\end{array}$ & $\begin{array}{c}8,26 \pm 0,11 \\
(1,34)\end{array}$ & $\begin{array}{c}8,49 \pm 0,13 \\
(1,52)\end{array}$ & $\begin{array}{c}8,58 \pm 0,16 \\
(1,83)\end{array}$ & $\begin{array}{c}8,50 \pm 0,18 \\
(2,11)\end{array}$ & $\begin{array}{c}8,35 \pm 0,12 \\
(1,44)\end{array}$ \\
\hline 5 & $\begin{array}{c}8,27 \pm 0,11 \\
\quad(1,28)\end{array}$ & $\begin{array}{c}8,34 \pm 0,14 \\
(1,72)\end{array}$ & $\begin{array}{c}8,35 \pm 0,19 \\
(2,27)\end{array}$ & $\begin{array}{c}8,44 \pm 0,12 \\
(1,36)\end{array}$ & $\begin{array}{c}8,41 \pm 0,20 \\
(2,40)\end{array}$ & $\begin{array}{c}8,34 \pm 0,15 \\
\quad(1,82)\end{array}$ \\
\hline 6 & $\begin{array}{c}8,13 \pm 0,22 \\
(2,70)\end{array}$ & $\begin{array}{c}8,41 \pm 0,15 \\
(1,74)\end{array}$ & $\begin{array}{c}8,26 \pm 0,16 \\
(1,88)\end{array}$ & $\begin{array}{c}8,36 \pm 0,20 \\
(2,41)\end{array}$ & $\begin{array}{c}8,33 \pm 0,21 \\
(2,51)\end{array}$ & $\begin{array}{c}8,43 \pm 0,13 \\
\quad(1,54)\end{array}$ \\
\hline 7 & $\begin{array}{c}8,49 \pm 0,18 \\
(2,11)\end{array}$ & $\begin{array}{c}8,51 \pm 0,11 \\
(1,31)\end{array}$ & $\begin{array}{c}8,33 \pm 0,17 \\
(2,09)\end{array}$ & $\begin{array}{c}8,30 \pm 0,14 \\
(1,74)\end{array}$ & $\begin{array}{c}8,32 \pm 0,17 \\
(2,10)\end{array}$ & $\begin{array}{c}8,32 \pm 0,15 \\
(1,84)\end{array}$ \\
\hline $\mathrm{X}$ & 8,29 & 8,38 & 8,37 & 8,41 & 8,44 & 8,41 \\
\hline $\mathrm{DP}$ & 0,11 & 0,10 & 0,11 & 0,10 & 0,10 & 0,10 \\
\hline \multirow[t]{3}{*}{$(\mathrm{CV} \%)$} & 1,35 & 1,22 & 1,29 & 1,24 & 1,21 & 1,24 \\
\hline & \multicolumn{3}{|c|}{ Espinheira-santa } & \multicolumn{3}{|c|}{ Maracujá } \\
\hline & Condição 1 & Condição 2 & Condição 3 & Condição 1 & Condição 2 & Condição 3 \\
\hline Dia & $\begin{array}{l}\bar{X} \pm \mathrm{DP} \\
(\mathrm{CV} \%)\end{array}$ & $\begin{array}{l}\bar{X} \pm \mathrm{DP} \\
(\mathrm{CV} \%)\end{array}$ & $\begin{array}{l}\bar{X} \pm \mathrm{DP} \\
(\mathrm{CV} \%)\end{array}$ & $\begin{array}{l}\bar{X} \pm \mathrm{DP} \\
(\mathrm{CV} \%)\end{array}$ & $\begin{array}{l}\overline{\mathrm{X}} \pm \mathrm{DP} \\
(\mathrm{CV} \%)\end{array}$ & $\begin{array}{l}\bar{X} \pm \mathrm{DP} \\
(\mathrm{CV} \%)\end{array}$ \\
\hline 1 & $\begin{array}{c}6,25 \pm 0,14 \\
(2,18)\end{array}$ & $\begin{array}{c}6,35 \pm 0,18 \\
(2,88)\end{array}$ & $\begin{array}{c}6,30 \pm 0,18 \\
(2,82)\end{array}$ & $\begin{array}{c}8,52 \pm 0,23 \\
(2,66)\end{array}$ & $\begin{array}{c}8,61 \pm 0,24 \\
(2,76)\end{array}$ & $\begin{array}{c}8,58 \pm 0,21 \\
(2,45)\end{array}$ \\
\hline 2 & $\begin{array}{c}6,23 \pm 0,16 \\
2,64\end{array}$ & $\begin{array}{c}6,31 \pm 0,10 \\
\quad(1,62)\end{array}$ & $\begin{array}{c}6,27 \pm 0,16 \\
(2,50)\end{array}$ & $\begin{array}{c}8,71 \pm 0,16 \\
\quad(1,78)\end{array}$ & $\begin{array}{c}8,59 \pm 0,18 \\
2,11\end{array}$ & $\begin{array}{c}8,59 \pm 0,22 \\
(2,58)\end{array}$ \\
\hline 3 & $\begin{array}{c}6,30 \pm 0,09 \\
(1,35)\end{array}$ & $\begin{array}{c}6,44 \pm 0,07 \\
\quad(1,09)\end{array}$ & $\begin{array}{c}6,40 \pm 0,18 \\
\quad(2,84)\end{array}$ & $\begin{array}{c}8,42 \pm 0,22 \\
\quad(2,58)\end{array}$ & $\begin{array}{c}8,74 \pm 0,17 \\
\quad(1,98)\end{array}$ & $\begin{array}{c}8,70 \pm 0,20 \\
\quad(2,27)\end{array}$ \\
\hline 4 & $\begin{array}{c}6,37 \pm 0,13 \\
\quad(1,97)\end{array}$ & $\begin{array}{c}6,28 \pm 0,14 \\
\quad(2,30)\end{array}$ & $\begin{array}{c}6,34 \pm 0,17 \\
\quad(2,65)\end{array}$ & $\begin{array}{c}8,46 \pm 0,13 \\
(1,49)\end{array}$ & $\begin{array}{c}8,58 \pm 0,18 \\
\quad(2,15)\end{array}$ & $\begin{array}{c}8,60 \pm 0,18 \\
(2,11)\end{array}$ \\
\hline 5 & $\begin{array}{c}6,26 \pm 0,19 \\
(2,99)\end{array}$ & $\begin{array}{c}6,49 \pm 0,07 \\
\quad(1,06)\end{array}$ & $\begin{array}{c}6,23 \pm 0,11 \\
(1,71)\end{array}$ & $\begin{array}{c}8,79 \pm 0,11 \\
\quad(1,24)\end{array}$ & $\begin{array}{c}8,62 \pm 0,18 \\
(2,07)\end{array}$ & $\begin{array}{c}8,51 \pm 0,15 \\
\quad(1,77)\end{array}$ \\
\hline 6 & $\begin{array}{c}6,34 \pm 0,07 \\
1,16\end{array}$ & $\begin{array}{c}6,22 \pm 0,17 \\
\quad(2,71)\end{array}$ & $\begin{array}{c}6,41 \pm 0,17 \\
(2,60)\end{array}$ & $\begin{array}{c}8,69 \pm 0,13 \\
(1,48)\end{array}$ & $\begin{array}{c}8,87 \pm 0,15 \\
\quad(1,71)\end{array}$ & $\begin{array}{c}8,59 \pm 0,17 \\
\quad(2,01)\end{array}$ \\
\hline 7 & $\begin{array}{c}6,47 \pm 0,12 \\
\quad(1,82)\end{array}$ & $\begin{array}{c}6,45 \pm 0,17 \\
(2,58)\end{array}$ & $\begin{array}{c}6,22 \pm 0,13 \\
(2,15)\end{array}$ & $\begin{array}{c}8,73 \pm 0,12 \\
(1,41)\end{array}$ & $\begin{array}{c}8,63 \pm 0,14 \\
(1,61)\end{array}$ & $\begin{array}{c}8,66 \pm 0,16 \\
(1,83)\end{array}$ \\
\hline $\mathrm{X}$ & 6,31 & 6,36 & 6,31 & 8,62 & 8,66 & 8,60 \\
\hline $\mathrm{DP}$ & 0,08 & 0,09 & 0,07 & 0,14 & 0,10 & 0,06 \\
\hline$(\mathrm{CV} \%)$ & 1,21 & 1,44 & 1,14 & 1,58 & 1,11 & 0,65 \\
\hline
\end{tabular}

Condição 1: Analista 1, Aparelho 1, Laboratório 1; Condição 2: Analista 2, Aparelho 1, Laboratório 1; Condição 3: Analista 1; Aparelho 2; Laboratório 2. Aparelho 1: Ohaus, MB45; Aparelho 2: Metllet Toledo, HB43; Analista 1: 1ª autora; Analista 2: colaboradora; Laboratório 1: Laboratório de Farmacognosia da UFSC; Laboratório 2: Laboratório Farmacêutico do Estado de Santa Catarina - LAFESC.

dos operadores durante quase todo o procedimento. Para a determinação do teor de água em drogas vegetais em estufa, propõe-se então, a realização da "Determinação da perda por dessecação”, considerando a análise concluída quando a diferença entre duas pesagens sucessivas for menor do que 5,0 mg, pois isto significa economia de tempo, energia, mão de obra e quantidade de amostra.

Quanto à determinação de água em analisador de umidade, a metodologia proposta, além de rápida e prática, mostrou-se exata e precisa, desde que os parâmetros de análise sejam prévia e corretamente estabelecidos. No entanto, a validação da metodologia deve ser feita para cada matéria-prima, de modo a confirmar se os parâmetros selecionados permitem a obtenção de resultados correspondentes aos obtidos através das metodologias farmacopéicas oficiais. 


\section{AGRADECIMENTOS}

Os autores agradecem ao Laboratório Farmacêutico do Estado de Santa Catarina - LAFESC, por permitir a realização das análises referentes à reprodutibilidade; Ao Prof. Dr. Maurício Sedrez dos Reis (Curso de Pós-Graduação em Recursos Genéticos Vegetais/UFSC) pelo apoio na análise estatística e a Andressa Gazola, como segundo analista e ao $\mathrm{CNPq}$ e Funcitec pelo apoio financeiro através do Plano Sul de pesquisa e Pós-Graduação (Processo: 521021/99-5).

\section{REFERÊNCIAS}

Berntsson O, Zackrisson G, Östling G 1997. Determinations of moisture in hard gelatin capsules using near-infrared spectroscopy: applications to at-line process control of pharmaceutics. J Pharm Biomel Anal 15: 895-900.

Bisset NG 1994. Herbal drugs and phytopharmaceuticals: a handbook on a scientific basis. Boca Raton: CRC; Stuttgart: Medpharm Scientific.

Brasil, Ministério da Saúde. Determina a publicação da lista de registro simplificado de fitoterápicos. Resolução RE, n. 89, de 16 de março de 2004. Disponível em: http://www.anvisa .goc.br/legis/index.htm. Acessado em setembro de 2004.

De Caro CA, Aichert A, Walter CM 2001. Efficient, precise and fast water determination by the Karl Fischer titration. Food Control 12: 431-436.

Farias MR 2003. Avaliação da qualidade de matérias-primas vegetais In: Simões, C.M.O. et al (Org.) 2003. Farmacognosia: da planta ao medicamento. 5.ed. Porto Alegre / Florianópolis: Ed. Universidade UFRGS/ Ed. da UFSC.

Farmacopéia Brasileira 1988. 4.ed. São Paulo: Atheneu, v.1. Farmacopéia Brasileira 2000a. 4.ed. São Paulo: Atheneu, v.1. Farmacopéia Brasileira 2000b. 4.ed. São Paulo: Atheneu, v.2. Farmacopéia Brasileira 2001. 4.ed. São Paulo: Atheneu, v.2. Farmacopéia Brasileira 2002. 4.ed. São Paulo: Atheneu, v.2.

Farmacopéia Portuguesa 2002. 7.ed. Lisboa: Ministério da Saúde, Instituto Nacional da Farmácia e do Medicamento. v.2.

International Conference on Harmonisation (ICH). Validation of analytical procedures: methodology. 1996. Disponível em: <http://www.ich.org/MediaServer. jser?@ID=418@TYPE=MULTIMEDIA\&@ TEMPLATE=616\&@ MODE=GLB $>$. Acessado em janeiro de 2004.

Isengard HD 1995. Rapid water determination in foodstuffs. Trends Food Sci Tecnol 6: 155-162.

Isengard HD, Färber JM 1999. Hidden parameters of infrared drying for determining low water contents in instant powders. Talanta 50: 239-246.

Isengard HD, Schulthei $\beta$ D, Radovic B, Anklam E 2001. Alternatives to official analytical methods used for the water determination in honey. Food Control 12: 459-466.

Isengard HD, Färber JM 2003. Water determination in products with high sugar content by infrared drying. Food Chem 82: 161-167. 